\title{
Thin-sections of painting fragments: opportunities for combined synchrotron-based micro-spectroscopic techniques
}

\author{
Emeline Pouyet $^{1 *}$, Barbara Fayard ${ }^{1,2}$, Murielle Salomé ${ }^{1}$, Yoko Taniguchi ${ }^{3}$, Francesco Sette ${ }^{1}$ and Marine Cotte ${ }^{1,4}$
}

\begin{abstract}
Synchrotron Radiation (SR) - based techniques such as SR- $\mu$ Fourier Transform InfraRed (FTIR) spectroscopy, SR- $\mu$ X-Ray Fluorescence (XRF), SR- $\mu$ X-Ray Absorption Near Edge Spectroscopy (XANES) and SR- $\mu$ X-Ray Diffraction (XRD) are increasingly used for the study of cultural heritage materials, as they offer enhanced spatial resolution and chemical sensitivity. For such analyses, painting fragments are usually prepared as thick (typically several hundreds of micrometers) polished cross-sections. The capabilities of these SR techniques can be significantly improved (enhanced data quality, reduced acquisition time, new imaging capabilities, improved lateral and in-depth resolution, reduced dose, etc.) if carried out on thin-sections, i.e. less than $\sim 30 \mu \mathrm{m}$ in thickness. This paper discusses and illustrates the different motivations in terms of related increased analytical capabilities for SR- $\mu F T I R, S R-\mu X R F, S R-\mu X A N E S$ and SR- $\mu$ XRD. Corollary to the optimization of the procedures for single SR micro-analytical technique, a specific discussion is focused on the challenges of their combination.
\end{abstract}

\section{Introduction}

As exemplified by the very high attendance to the 2013 Technart conference, the study of materials in art and archaeology is increasingly benefiting from analytical spectroscopic techniques. Beyond the different materials studied (dyes, stones, metals, glass, ceramics, resins, wood, synthetic materials, etc.), paintings usually present a complex and heterogeneous microstructure which complicates their chemical characterization. Therefore spatially resolved chemical techniques, combining spectroscopy and microscopy, are very well suited to attain a full 2D or 3D description of the constitution of painting fragments. Both the composition and the spatial organization of the multilayered complex mixtures are probed. In this context, SR-based imaging techniques, in particular $\mu$ FTIR, $\mu$-XRF, $\mu$-XANES and $\mu$-XRD, have been used to an increasing extent within the last decades to analyse painting fragments $[1,2]$. While the typical scale of heterogeneity of painting material is in the range of a few microns, the extremely bright and collimated synchrotron source offers an appropriate high spatial resolution (a few

\footnotetext{
* Correspondence: pouyet@esrffr

${ }^{1}$ European Synchrotron Radiation Facility, 71, avenue des Martyrs, Grenoble F-38000, France

Full list of author information is available at the end of the article
}

$\mu \mathrm{m}$ down to some tens of $\mathrm{nm}$ ) as well as very low detection limits (a few ppb for XRF analyses). Moreover, the energy tunability of the source allows spectroscopic analyses to be carried out in a wide energy domain, ranging from the infrared to hard X-ray beams.

In recent years, the combined access on a multi-modal platform to both X-ray and vibrational micro spectroscopies has become a main asset in the characterization of painting samples. However, such combination can be improved through dedicated efforts on instruments, data analyses software packages and on sample preparation. Regarding the last point, painting fragments are historically and usually prepared and analysed as polished thick sections. In this work, the opportunities related to the study of thin-sections (a few microns thickness) are addressed.

The preparation of samples as thin-sections is a standard approach in varied scientific fields, as in i) geological research, in particular petrography for which thinsection is a useful methodology for the study and classification of a wide variety of materials, including rocks, minerals, slags, concrete, mudbrick, and plaster, as well as fired clays, and in ii) biomedical research, and in particular histological studies, where the preparation of 
thin-sections is of prime interest for imaging techniques since it allows working at definite thickness and correlatively preserved and defined cellular and structural levels [3]. Derived from these two domains, the preparation of thin-sections has been extended to artistic materials [4] (stone, ceramics [5], wood [6]), as well as ancient biomaterials (tissue from mummies [7], hairs [8], bones [9], textiles, parchment [10]). Over the last ten years different protocols have been proposed to prepare thinsections of painting fragments: by pressing a fragment in an anvil diamond cell [2,11-13], by reducing sample thickness following a double-polishing approach [14], or using a microtome [15-18]. Our group has recently proposed two protocols for the optimized preparation of painting thin-sections [17]. However, the complexity of preparing thin-sections compared with cross-sections hinders its introduction as a standard approach. Here, we would like to highlight, on the primary basis of SRbased $\mu$ FTIR, $\mu$ XRF, $\mu$ XANES and $\mu$ XRD analyses, that the preparation of thin-sections opens new ways to examine samples from historical paintings using hyperspectral elemental, molecular and structural methods and that even if it is more difficult to implement, deserves being considered. After a general discussion of the enhanced capabilities of each technique when carried out on thin-sections, a specific discussion will be focused on combining their results.

\section{Synchrotron-radiation micro-imaging techniques for the analysis of painting fragments: Advantages of thin-sections over cross-sections}

Micro fourier transform InfraRed spectroscopy

Principles of FTIR and applications to painting

fragments FTIR is routinely applied for obtaining information on the presence of molecular groups by the excitation and the identification of their characteristic vibrational modes. Stretching vibrations are explained using a simple model which consists in describing a covalent bond as a simple harmonic oscillator, with two atoms of mass $M$ and $m$ respectively connected with a spring of strength $k$. According to Hooke's law, the frequency of the spring vibration $v$ is expressed as:

$$
v=\frac{1}{2 \pi} \sqrt{\frac{\mathrm{k}}{\mu}} \text { with } \mu=\frac{m M}{m+M}
$$

This simple model may be used to describe diatomic molecules, but becomes more complicated for complex polyatomic molecules. However, this equation gives a first primary link between atom nature, chemical bonds and stretching vibration frequency.

FTIR spectroscopy has been used for the analysis of artistic materials since the 1960's, and FTIR-microscopy was soon identified as a very promising method [19]. The 2D mapping capabilities offered by the development of coupling a microscope to a FTIR spectrometer allowed both the selective determination and localization of compounds present in mixtures. Probing simultaneously mixtures of organic, inorganic and hybrid materials, this technique is extensively used for its versatility and its non-invasiveness to study end-products of controlled or long term reactions of organic binders with mineral pigments (e.g. in cosmetics [20] or in paintings [21]). The limited lateral resolution (on the order of $100 \mu \mathrm{m}$ ) offered by laboratory sources has hindered its extension to the microscopic analysis in $\mathrm{CH}$ studies [22]. The implementation of FTIR end-stations at synchrotron facilities, in the 1990's, was a real achievement offering a significant improvement regarding lateral resolution (down to a few microns). The natural low divergence and corollary high brightness of synchrotron radiation, 2-3 orders of magnitude higher than with the internal source of laboratory spectrometers (Globar), allowed improved lateral resolution and signal to noise ratio (SNR). It was soon exploited for the analysis of artworks [22,23].

In parallel much effort has been made to further improve the capabilities of laboratory FTIR microscopes, mainly through the introduction of Focal Plane Array (FPA) detectors. Such microscopes enable reaching lateral resolution of the order of $10 \mu \mathrm{m}$, and are therefore very competitive with synchrotron instruments [24]. Thanks to these different developments, $\mu$ FTIR is becoming a standard technique for the $2 \mathrm{D}$ characterization of molecular groups in paint samples, and in particular for the mapping of organic materials. It provides a good complement to Scanning Electron Microscopy coupled with an Energy Dispersive Spectrometer (SEM-EDS) which is routinely used for the 2D elemental analysis of the inorganic components of painting fragments.

\section{Different acquisition modes available, for an identical result?}

The $\mu$ FTIR analysis of painting fragments can be carried out in three main modes: in specular reflection, in Attenuated Total Reflectance (ATR), or in transmission [25]. As an illustration, Figure 1 shows sum spectra (with 50 scans per spectrum and $0.8 \mathrm{~cm}^{-1}$ spectral resolution) acquired in the three configuration modes on the same $3 \mu \mathrm{m}$ section of a model painting, made of lead white mixed with linseed oil (mass ratio 0.5:1).

Specular reflection mode relies on the measurements of refractive index changes at the sample surface associated with absorption bands. Consequently, acquisitions can be performed on cross-sections or sample surfaces, without need for physical contact, which represents its main advantage compared with the two other acquisition schemes $[14,19,26-28]$. However, spectra appearance can 

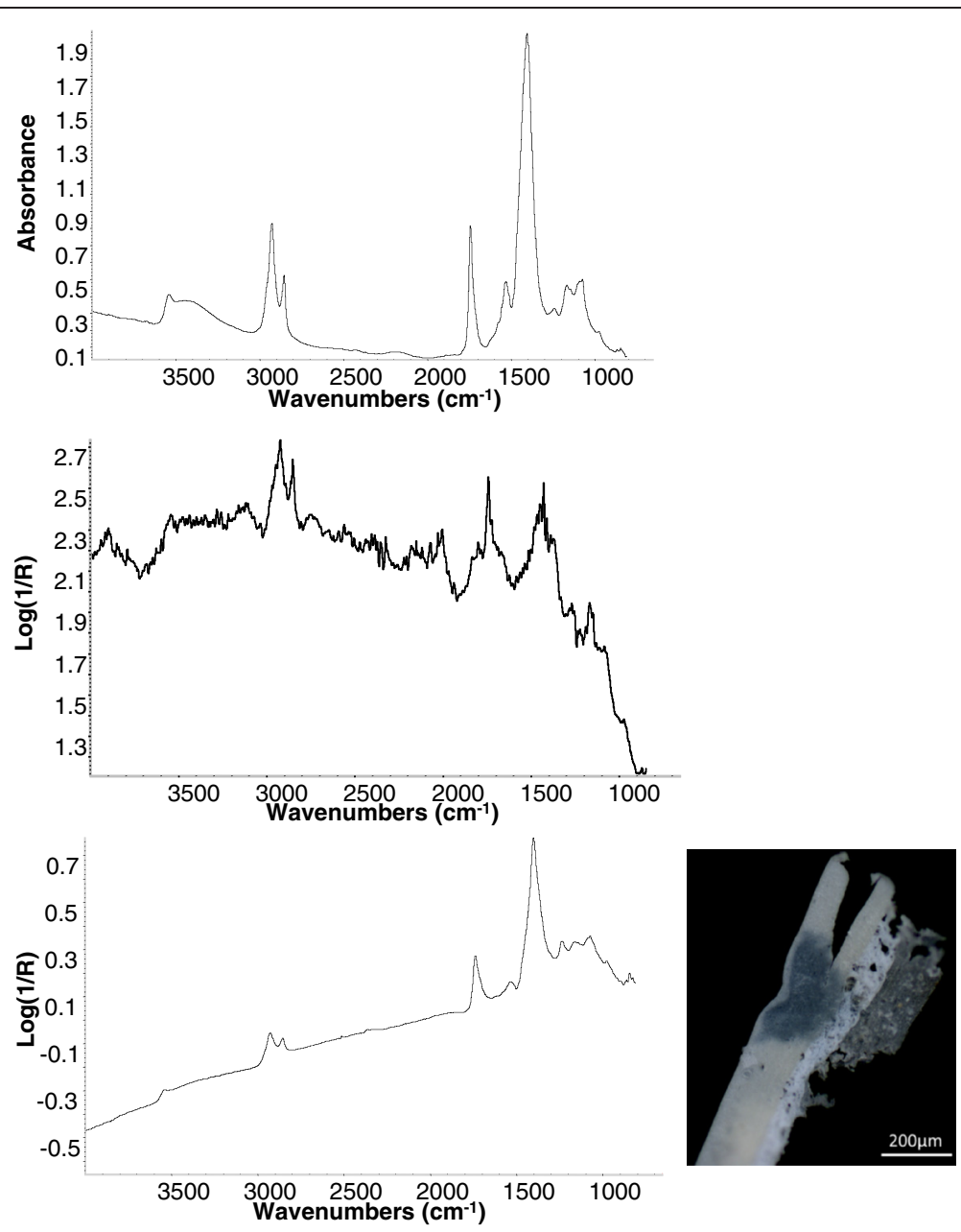

Figure 1 FTIR analyses of a $3 \mu \mathrm{m}$-thick thin-section of a lead white model painting (lead white mixed with linseed oil, ratio: 0.5:1). The three spectra are a sum of 3 pixels selected in 3 maps acquired in 3 different acquisition modes, with SR beam: a) transmission mode (beam size: $10 \times 10 \mu \mathrm{m}^{2}$, pixel size: $10 \times 10 \mu \mathrm{m}^{2}$ ), b) specular reflection mode (beam size: $10 \times 10 \mu \mathrm{m}^{2}$, pixel size: $10 \times 10 \mu \mathrm{m}^{2}$ ), and c) ATR mode (beam size: $28 \times 28 \mu^{2}$, with Ge crystal, pixel size: $10 \times 10 \mu \mathrm{m}^{2}$ ), on the right side is presented a visible light microscope image of the thin-section after ATR measurements, the dark central area represents contact region with Ge-crystal.

be modified as a function of the relative amounts of surface reflection and of radiation that has penetrated the sample. Consequently, spectral information can be difficult to interpret due to the presence of diffuse reflection, refraction, or scattering effects [29]. The sensitivity of the FTIR technique in reflection mode is also affected and is typically 3-4 orders of magnitude less than in transmission mode. In comparison with the two other modes (Figure 1b), spectra present indeed a lower SNR. It can be improved with optimized sample preparation, but, when compared to ATR mode, it still does not compete in terms of sensitivity and achievable lateral resolution [26].

ATR mode relies on the absorption measurement of an evanescent wave generated at the interface of a crystal in contact with the sample surface. The penetration depth of the evanescent wave into the sample typically ranges from
0.5 to $2 \mu \mathrm{m}$, and varies depending on the beam wavelength, its angle of incidence and the indices of refraction of both ATR crystal and sample probed. A plane and smooth sample surface is the main constraint for ATR measurement, explaining the increasing use of this device for the analysis of cross-sections [28-32]. This step is nevertheless crucial. Analyses in ATR mode may be indeed complex due to: i) the need for a high-quality contact between sample and crystal (any trapped air would distort the spectra), ii) the risk to bend the sample, under the pressure of the tip (as seen in Figure 1c); iii) the risk to contaminate the tip during a raster scanning map with the long dwell time associated to moving the stage up and down at every pixel in this configuration, and iv) the possible mismatch between visible and infrared images [28]. Data treatment of ATR data also presents some challenges as spectra acquired in ATR mode may differ from those 
obtained in transmission mode, with a distortion of the relative intensities of bands and an introduction of a shift to lower frequencies [2]. The relative intensity shift is known and readily corrected in several softwares. The shift in frequency, which can result in a displacement of the peak maximum by several wavenumbers, is though hard to correct for unknown compounds.

While following discussion will be oriented towards measurements in transmission mode, performing $\mu$ FTIR in ATR mode on thin-section should be considered as a complementary method in the future. Thanks to a fourfold improvement of the spatial resolution, with Ge crystal, and the possibility to work on thicker sections, ATR measurements would present a step forward for the combination with X-ray based methods.

Alternatively to reflection and ATR modes, $\mu$ FTIR analysis of painting fragments can be performed in transmission mode (Figure 1a). As this method necessitates the beam crosses the sample, it is more demanding in term of sample preparation and requires thin-section preparation. In this case, the simple correlation between the beam absorption and the thickness of the sample is established, which facilitates semi quantitative analysis of the results. Thus concentration of a particular molecular bonding is proportional to the integral of its absorption peak. Moreover, even if the increasing use of portable in-situ FTIR equipments in the field of Cultural Heritage $(\mathrm{CH})$ is pushing for the development of databases in diffuse reflectance mode, the most famous databases were acquired in transmission mode (e.g. IRUG, the Infrared and Raman Users Group (http://www.irug.org/), the IBeA, Ikerkuntza eta Berrikuntza Analitikoa [33]). In this case, spectra can be directly compared to reference spectra from databases.

The recent combination of bright SR source with FPA detectors, at the Synchrotron Radiation Center (SRC, Stoughton, USA), requires also thin-sections preparation as the analyses are carried out in transmission mode. With a unique design of an array of 12 SR beams, it creates a homogeneous beam over a large field of view. Recently successfully employed for the analysis of a model painting fragment and some historic paint samples, this approach offers new formidable performance in terms of spatial resolution and acquisition time [34,35].

\section{Assessment of the optimum thickness for FTIR analyses in transmission mode}

Analysis in transmission mode requires the beam to go through the sample. This imposes some constraints and challenges in term of sample preparation. In contrast to $\mathrm{X}$-ray analyses, the determination of an optimum thickness through theoretical calculation is not straightforward, and an experimental approach, based on the preparation of sections of different thicknesses is usually more efficient. In the case of paintings, a typical thickness ranging from 2 to $20 \mu \mathrm{m}$ is needed to limit over-absorption and related artefacts [36]. The thickness choice is indeed challenging and can require preliminary tests on the largest samples of the corpus in order to identify the correct thickness required to avoid over- or under-absorption issues. As an example, FTIR maps were obtained on the same model painting sample (lead white mixed in linseed oil, ratio: 1:1), for different section thicknesses, from 3 to $8 \mu \mathrm{m}$. The structure of the section is visible on both optical (Figure 2a) and SEM images (Figure 2b): the dotted white line outlines the limit between the priming layer, from the canvas (bottom layer), and the lead white based paint layer (top layer). The spectra were specifically extracted from the latter for different thickness values (Figure 2c). In this case, a maximum thickness of $3 \mu \mathrm{m}$ is appropriate to avoid over-absorption which would result in a deformation of characteristic $\mathrm{C}-\mathrm{H}$ and $\mathrm{C}=\mathrm{O}$ bands.

\section{Micro X-Ray fluorescence \\ Principles of XRF and applications to painting fragments}

XRF results from the excitation of an inner shell of an atom by the ejection of an electron from this inner shell. The de-excitation of the atom by the transition of an electron from a higher shell leads to the emission of an XRF photon of energy characteristic of the excited element. It is non-destructive, and when performed with micro-focused beams at synchrotron sources, enables obtaining elemental $2 \mathrm{D}$ or $3 \mathrm{D}$ images at sub-micrometre scale with enhanced detection limits (down to $\mathrm{ppb}$ ). When performing $\mu$ XANES or $\mu$ XRD analyses (cf. below), their combination with $\mu \mathrm{XRF}$ is usually straightforward and provides an elemental mapping preliminary or complementary to molecular and structural analyses respectively.

In the case of paintings, XRF is commonly performed on thick cross-sections. In addition to the major elements identification, e.g. those entering into the composition of pigments [37], it allows probing the localisation of less concentrated elements such as environmental contaminants, degradation products and trace elements that could bring important information on the pigment's history (provenance, production, etc.) [38].

\section{Theoretical and experimental assessment of an optimum thickness for $\mu \mathrm{XRF}$ analyses}

From a theoretical point of view [39], the relation between XRF intensity of a given emission line and the element weight concentration in the specimen can be calculated as follows. Considering a monochromatic collimated X-ray beam, with intensity $\mathrm{I}_{0}$ at the incident energy $\mathrm{E}_{0}$, crossing a homogeneous object of interest with a penetration angle $\varphi$ (Figure 3), the incident radiation is gradually absorbed by the specimen (represented as a 

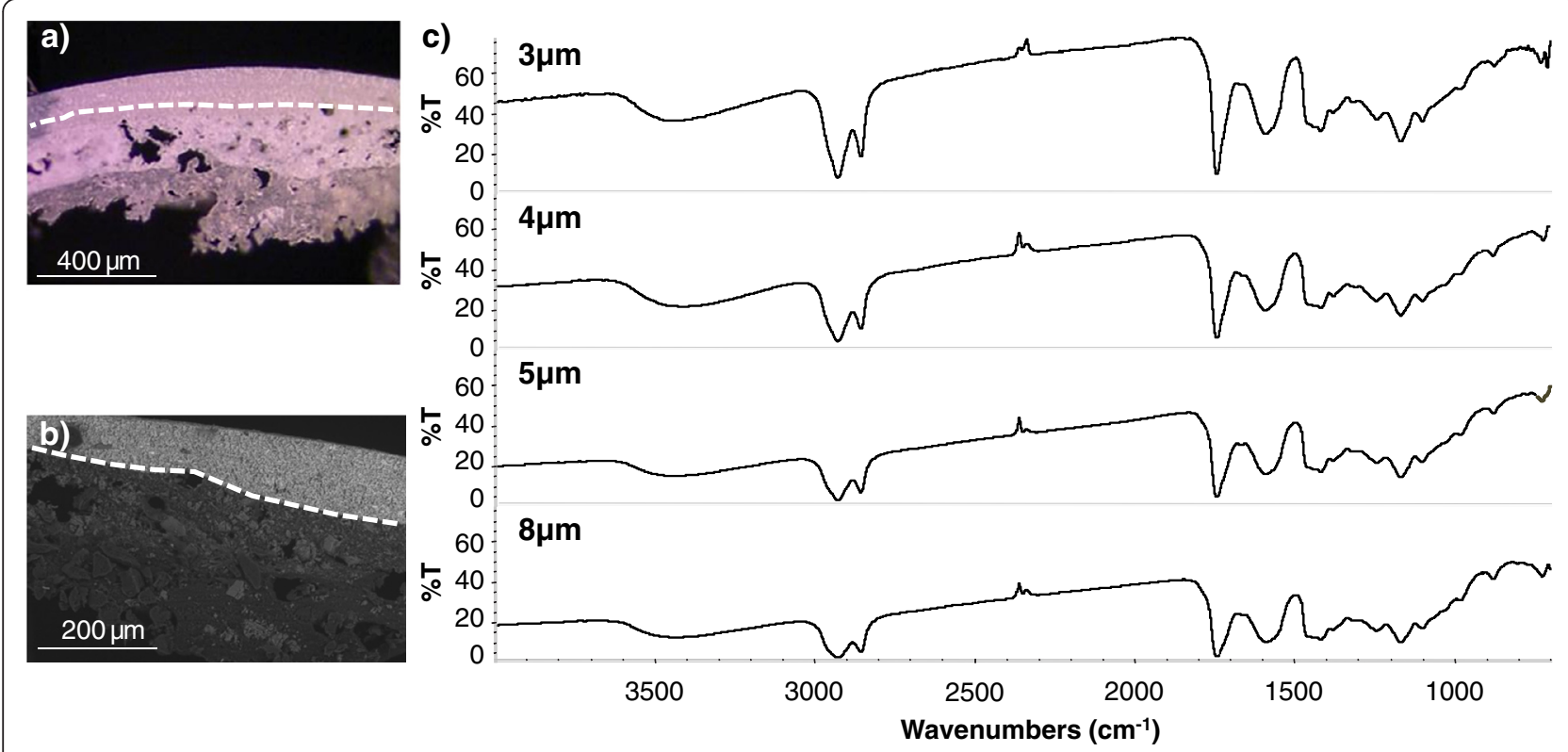

Figure 2 Example of $\mu \mathrm{FTIR}$ transmission spectra of thin-sections of a lead white model painting. a) Visible light microscope and $\mathbf{b}) \mathrm{SEM}$ images of the $3 \mu \mathrm{m}$-thick section; the dotted line highlights the separation between the paint layer and the ground layer. c) FTIR spectra on 3 to $8 \mu \mathrm{m}$-thick sections with a $8 \times 8 \mu \mathrm{m}^{2}$ beam size.

progressively lightening black line in Figure 4a). At a distance $t$ from the surface, the remaining fraction $\mathrm{I}_{\mathrm{t}}\left(\mathrm{E}_{0}\right)$ is given by the Beer Lambert law:

$$
I_{t}\left(E_{0}\right)=I_{0}\left(E_{0}\right) e^{-\frac{\mu_{s}\left(E_{0}\right) \rho_{s} t}{\sin \phi}}
$$

where $\mu_{s}\left(E_{0}\right)$ is the mass attenuation coefficient $\left(\mathrm{cm}^{2} . \mathrm{g}\right)$ of the sample at $\mathrm{E}_{0}$ defined as $\mu_{s}=\frac{\mu_{i i}}{\rho_{c}}$, with of $\mu_{\mathrm{li}}$ the linear absorption coefficient and $\rho_{\mathrm{s}}{ }_{\mathrm{\rho}}\left(\mathrm{g} . \mathrm{cm}^{-3}\right)$ the sample density.

The element of interest i absorbs, between $t$ and $(t+d t)$, a fraction of the incident beam given by: $\frac{W_{i} \mu_{i}\left(E_{0}\right) \rho_{s} d t}{\sin \phi}$, where $\mu_{i}\left(E_{0}\right)$ is the mass attenuation coefficient of the element of interest, and $W_{i}$ its mass fraction.

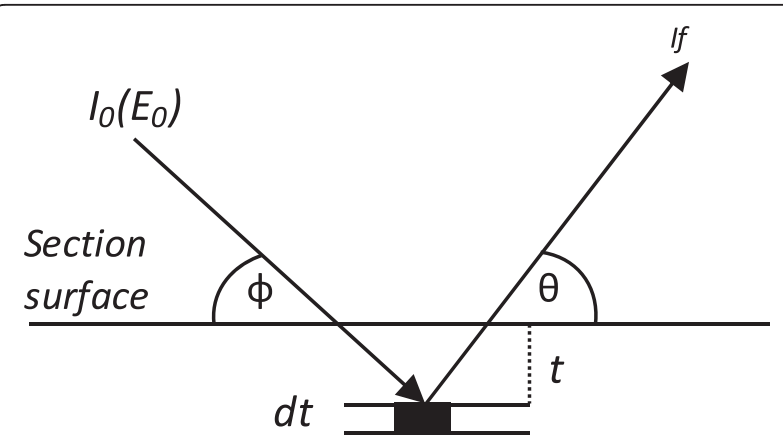

Figure 3 Schema of the primary XRF emission geometry mentioned in the eqn. 5 .
From the photons absorbed, only a fraction will lead to the emission of XRF photons, this fraction will be designated as $Q_{i}$. From this part, photons emitted at the energy $\mathrm{E}_{\mathrm{f}}$ in the volume from $(t, t+d t)$ will be partially re-absorbed following: $e^{-\frac{\mu_{s}\left(E_{f}\right) P_{s} t}{\sin \theta}}$, where $\theta$ is the detector angle with respect to the sample surface and $\mu_{s}\left(E_{f}\right)$ is the mass attenuation coefficient of the sample for XRF photons with energy $E_{f}$. Assuming isotropic XRF emission, only a fraction is emitted towards the detector solid angle $\Omega$, given by $\Omega / 4 \pi$. The contributions from surface and bottom layers of the specimen can be summed as follows, by integrating the different contributions over $d t$, following the assumption that the sample is homogeneous over the thickness defined:

$$
\begin{aligned}
I_{f}\left(E_{0}\right)= & I_{0}\left(E_{0}\right) \frac{\Omega}{4 \pi} Q_{i} \frac{W_{i} \mu_{\mathrm{i}}\left(E_{0}\right)}{\left(\frac{\mu_{\mathrm{s}}\left(E_{0}\right)}{\sin \phi}+\frac{\mu_{\mathrm{s}}\left(E_{f}\right)}{\sin \theta}\right)} \\
& \times\left(1-e^{-\left(\frac{\mu_{s}\left(E_{0}\right)}{\sin \phi}+\frac{\mu_{s}\left(E_{f}\right)}{\sin \theta}\right) \rho_{\mathrm{s}} \mathrm{t}}\right)
\end{aligned}
$$

Eqn. 2 shows that, in the simple model considered, the probability of detecting an XRF photon depends on different experimental aspects, and in particular on the sample absorption of both incoming X-Ray photons and emitted XRF photons (the presence of filters or the efficiency of the detector are not considered here). 


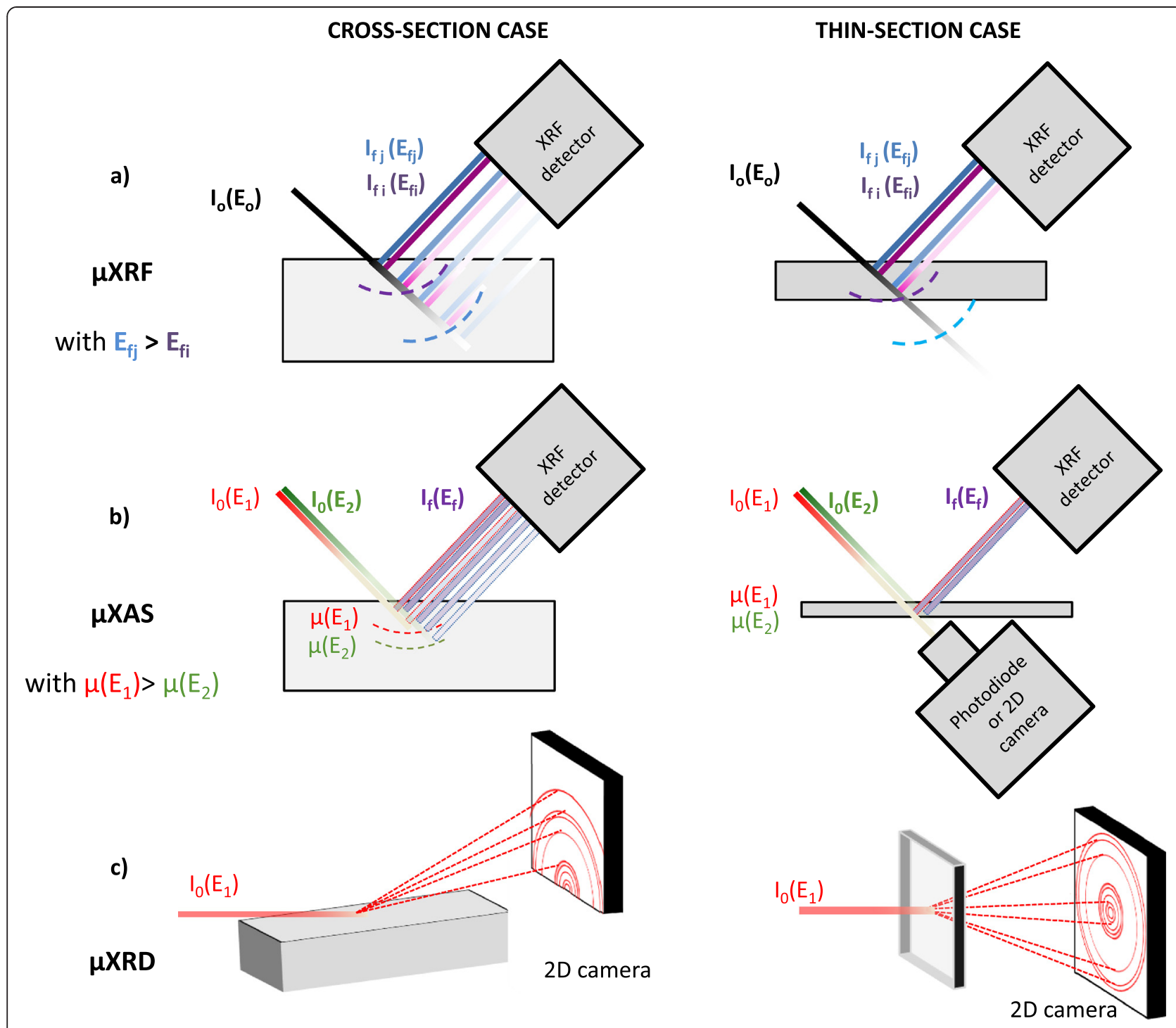

Figure 4 Schema of experimental conditions for paint analysis by a) SR- $\mu$ XRF, b) SR- $\mu$ XANES (both in top view, in 2D), c) SR- $\mu$ XRD (side view, in 3D) for both cross (left) and thin (right) section cases.

The 3D distribution and nature of heterogeneous elements constituting the matrix as well as the granulometry of the mixture can therefore complicate XRF quantification, in particular in the case of mixtures of low $\mathrm{Z}$ and high $\mathrm{Z}$ elements.

The eqn. 2 presented above can be simplified in two cases: the thin-sample and thick-sample approaches [39].

In the case of an infinite-target (thick sample), a thickness can be defined as a limiting value above which no further increase in the intensity of the characteristic $\mathrm{XRF}$ radiation is observed when increasing thickness. In this case $\left(\frac{\mu_{s}\left(E_{0}\right)}{\sin \phi}+\frac{\mu_{s}\left(E_{f}\right)}{\sin \theta}\right) \rho_{\mathrm{s}} \mathrm{t}>>1$ and the exponential term goes to 0 , so that eqn. 2 is simplified as:

$$
I_{f}\left(E_{0}\right)=I_{0}\left(E_{0}\right) Q_{i} \frac{\Omega}{4 \pi} \frac{W_{i} \mu_{\mathrm{i}}\left(E_{0}\right)}{\left(\frac{\mu_{\mathrm{s}}\left(E_{0}\right)}{\sin \phi}+\frac{\mu_{\mathrm{s}}\left(E_{f}\right)}{\sin \theta}\right)}
$$

Consequently, the analysis of thick cross-section may relate to the analysis of infinite target, which may simplify XRF quantification. However, this equation is verified only for homogeneous sample and may be strongly affected by heterogeneities along beam path.

In the opposite, in the thin-target case, $\left(\frac{\mu_{s}\left(E_{0}\right)}{\sin \phi}+\frac{\mu_{s}\left(E_{f}\right)}{\sin \theta}\right)$ $\rho_{s} t<<1$ using the Taylor series expansion, the term 


$$
\begin{aligned}
& \left(1-e^{-\left(\frac{\mu_{s}\left(E_{0}\right)}{\sin \phi}+\frac{\mu_{s}\left(E_{f}\right)}{\sin \theta}\right) \rho_{s} t}\right) \quad \text { can be approximated to } \\
& \left(\frac{\mu_{s}\left(E_{0}\right)}{\sin \phi}+\frac{\mu_{s}\left(E_{f}\right)}{\sin \theta}\right) \rho_{s} \mathrm{t} \text { and eqn. } 2 \text { is simplified as: } \\
& I_{f}\left(E_{0}\right)=I_{0}\left(E_{0}\right) Q_{i} \frac{\Omega}{4 \pi} \rho_{s} W_{i} \mu_{i}\left(E_{0}\right) \mathrm{t}
\end{aligned}
$$

The intensity of the characteristic X-ray depends, in a first approximation, linearly on the concentration of the element of interest, i.e. matrix effects can be neglected.

Simplifying eq. 2 into eq. 4 is possible when the total mass per unit area satisfies:

$$
m_{\text {thin }}<\frac{0.1}{\frac{\mu_{s}\left(E_{0}\right)}{\sin \phi}+\frac{\mu_{s}\left(E_{f}\right)}{\sin \theta}}
$$

with $\mathrm{m}_{\text {thin }}=\rho_{\mathrm{s}} \mathrm{t}$.

To give an order of magnitude in the context of paintings, these maximum thicknesses were calculated, using eqn. 5 for a set of common ingredients found in paintings: lead-based pigments $\left(\mathrm{PbCO}_{3}, \mathrm{~Pb}_{3} \mathrm{O}_{4}, \mathrm{PbSO}_{4}\right)$, quartz $\left(\mathrm{SiO}_{2}\right)$, atacamite $\left(\left(\mathrm{CuCl}(\mathrm{OH})_{2}\right)\right.$, considering the following conditions $\phi=\theta=45^{\circ}$. For all pigments presented, low energy XRF photons $(<5 \mathrm{keV}$, being from K-emission of low $\mathrm{Z}$ elements or $\mathrm{L}, \mathrm{M}$ emission of high $\mathrm{Z}$ elements) are strongly reabsorbed by the pigments limiting thin-sample case to section thickness of a few microns: typically $0.5 \mu \mathrm{m}$ for lead-based pigments considering the $\mathrm{Pb} \mathrm{M}_{\alpha}$ emission line $(2.345 \mathrm{keV}), 1 \mu \mathrm{m}$ of quartz for the Si $\mathrm{K}_{\alpha}$ emission line $(1.739 \mathrm{keV}), 1 \mu \mathrm{m}$ of atacamite for the $\mathrm{Cl} \mathrm{K} \mathrm{K}_{\alpha}$ emission line $(2.622 \mathrm{keV})$ and $5 \mu \mathrm{m}$ for the $\mathrm{Cu} \mathrm{K} \mathrm{K}_{\alpha}$ emission line $(8.047 \mathrm{keV})$. Whereas $\mathrm{Cu} \mathrm{K}_{\alpha}$ emission photons $\left(E_{\mathrm{f}}=8.047 \mathrm{keV}\right)$, escape from a $5 \mu \mathrm{m}$ thick section without being strongly absorbed by surrounding matrix, $\mathrm{Cl} \mathrm{K}$ emission photons $\left(\mathrm{E}_{\mathrm{f}}=2.622 \mathrm{keV}\right)$ are almost completely absorbed for the same thickness (with almost $~ 80 \%$ of the XRF photons absorbed on the radiation path). Consequently, even if $\mathrm{K}$ emission lines of heavy elements (copper, iron, etc.) can escape from high depth into the sample, the contribution of the lighter elements is limited to the near surface, few microns or tenths of microns, limiting thin-sample case to very thin-section.

The high penetration depth of X-ray may be an asset compared to electron probes, for example since it allows $3 \mathrm{D}$ analysis of relatively thick samples. However, the high penetration depth of X-ray complicates quantification measurements. In this context, $2 \mathrm{D} \mu \mathrm{XRF}$ of thin-sections can enable more reliable elemental co-localisation, quantitative analyses, with better spatial resolution. With the worldwide development of SR-nanoprobes, the issue of more and more asymmetric voxels will be even further critical and the preparation of ultra thin samples should be considered.

\section{Micro-X-Ray absorption spectroscopy Principles of X-Ray absorption spectroscopy and applications to painting fragments}

X-ray Absorption Spectroscopy (XAS) consists in measuring the variation of the X-ray absorption coefficient of an element of interest while scanning the energy of the probing X-ray photons around one of its absorption edges. With the absorption of an X-ray photon, a core electron is excited into unoccupied electronic states or into the vacuum continuum. XANES focuses on a $\sim 100 \mathrm{eV}$ region around the edge and provides information regarding the bonding environment (oxidation state, coordination numbers, site symmetry, and distortion) of the given element. Synchrotron sources offer not only the necessary continuous spectral range, but also the necessary intensity to allow high spectral and lateral resolution and in conjunction with effective detection limits (in particular when XANES experiments are performed in XRF detection mode).

With respect to the analysis of paintings, this technique is employed to understand processes taking place in the creation and in the degradation of pigments. Because both degradation and fabrication processes (choice of raw compounds, reactions, temperature, atmospheric conditions etc.) are usually based on oxidation-reduction reactions, XANES analysis is a powerful tool to understand the full life of the painting [40].

The possibility to easily switch from unfocused mode (millimetre scale) to focused mode (sub-micrometre scale) is a real asset for the study of such heterogeneous materials. For example, this combination was exploited to analyse degraded Pompeian paintings, the millimetre beam being used for a macroscopic surface analysis of the paintings, and the sub-micrometre beam for an indepth study of the painting transverse cross-sections [41]. Furthermore, within the range of analytical techniques used for elemental speciation, XANES is polyvalent, applicable to a large range of materials, without constraints in term of samples long range order (unlike $\mathrm{X}$-ray diffraction). For instance, while most inorganic pigments are well crystallised compounds, there are also a few amorphous pigments which can be well investigated by such a technique. This is for instance the case of the smalt, a powdered blue potash glass coloured by the presence of cobalt ions [42].

\section{Determination of an optimum thickness for XANES measured in XRF mode}

XANES analysis requires an accurate measurement of $\mu_{\mathrm{li}}(\mathrm{E})$, the linear absorption coefficient which corresponds to the probability that X-ray are absorbed or scattered by the element of interest. It is related to the transmittance according to Beer's Law developed in eqn. (1). $\mu_{\mathrm{li}}$ (E) can be determined in different configurations, either directly by measuring the sample transmission, or indirectly, e.g. 
by measuring XRF or electron yields, as a function of the energy of the incoming $\mathrm{X}$-ray.

In most cases, painting samples are prepared as polished cross-sections, preventing any measurement in transmission. Measurements are usually carried out in XRF mode [40]. In such a case, it is generally assumed that the linear X-ray absorption coefficient $\mu_{l i}(E)$ is proportional to the emitted XRF yield $I_{f}$ as:

$$
\mu_{l i}(E) \propto \frac{I_{f}}{I_{0}}
$$

However, for a thick-section where the element of interest is concentrated, which is the case in many experiments related to the study of pigments, this relation is not verified and related problem of self-absorption should be considered.

As explained above in the XRF section, depending on the sample composition the XRF signal can be attenuated and the detected signal will depend on the escape depth of those photons. However, self-absorption term mainly refers to the attenuation of the incoming beam and not of emitted photons. It is encountered when the element of interest is mainly responsible for the penetration depth into the sample (Figure $4 \mathrm{~b}$ ). This effect reduces the difference of XRF intensity measured between spectral regions where the absorption coefficient is high or low. By damping the amplitude of the X-ray absorption fine structure oscillations, it severally distorts XANES spectra which may lead to incorrect XANES peak sizes, attenuated XANES amplitude, uncertainty in determination of coordination number and wrong standards spectra for linear combination or for PCA target transform. This effect is illustrated in Figure 5 which represents the XANES spectra of a $4 \mu \mathrm{m}$ thick manganese foil acquired at the Mn K-edge, both in transmission mode and in XRF mode. In this example, selfabsorption effect leads to a clear decrease of the XANES

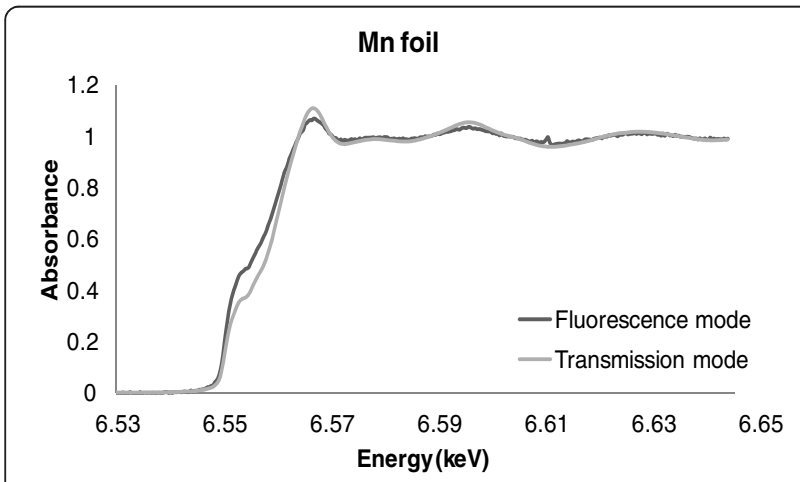

Figure 5 Typical K-edge XANES spectrum of Mn pure metallic foil acquired in the same acquisition condition in XRF and in transmission modes. oscillations in the spectrum acquired in XRF in comparison with the spectrum acquired in transmission. As sample composition is well characterized correction procedures can be applied to recover the true sub-shell photo absorption coefficient. This procedure is complicated or even impossible in the case of complex samples with partially unknown compositions. In this context, the analysis of thin-section validating the thin-sample limit considered in eqn. 4 , directly yields to a linear relationship between $\mu_{\mathrm{li}}$ and $\mathrm{I}_{\mathrm{f}}$, as denoted in eqn. 6. Consequently, the preparation of thin-section respecting the criteria of eqn. 5 may improve XRF measurements.

As a general rule if a sample, composed of a pure element $\left(\mu_{\mathrm{s}}=\mu_{\mathrm{i}}\right)$ in a geometry for which $\phi=\theta=45^{\circ}$, absorbs $\sim 10 \%$ of primary beam at edge energy, selfabsorption reduces the signal by about $5 \%$, which is already enough to introduce noticeable errors into the analysis [43].

In conclusion when the element of interest is concentrated in the sample, performing XANES analyses in XRF mode on thin-sections of appropriate thickness allows substantially reducing the systematic effects which can degrade the analysis of XANES features in XRF mode [44].

\section{Determination of an optimum thickness for XANES acquisition in transmission mode}

Alternatively to XRF mode, measuring XANES spectra in transmission allows: i) circumventing the self-absorption issue, and ii) limiting probed volume. For relevant transmission measurements, the sample thickness is also a key factor which should be carefully defined to achieve the optimal transmission intensity. The sample thickness is determined by two guidelines:

- the X-ray should not be fully absorbed by the sample, which could then cause a distortion of the XANES features called over-absorption effects. A typical absorbance maximum value of $\mu_{\mathrm{li}} \mathrm{t} \sim 2-2.5$ is usually advised (corresponding to transmission value in post-edge superior to $8 \%$ ).

- on the other hand, the contrast at the edge should be as large as possible: [ $\mu_{\mathrm{li}}$ (above edge) - $\mu_{\mathrm{li}}$ (below edge)] $\sim 1$ (corresponding to a ratio of the transmission above the edge vs. transmission below the edge of $36 \%$ ). A too thin-section would reduce absorption edge value and consequently XANES spectrum SNR.

From these considerations, the feasibility of XANES recorded in transmission mode will be highly dependent on: the element and the edge of interest, the concentration of this element, and the nature of the matrix.

Figure 6 presents theoretical X-ray transmission in the geometry $\phi=\theta=45^{\circ}$ through a thickness of $1,5,10$, 


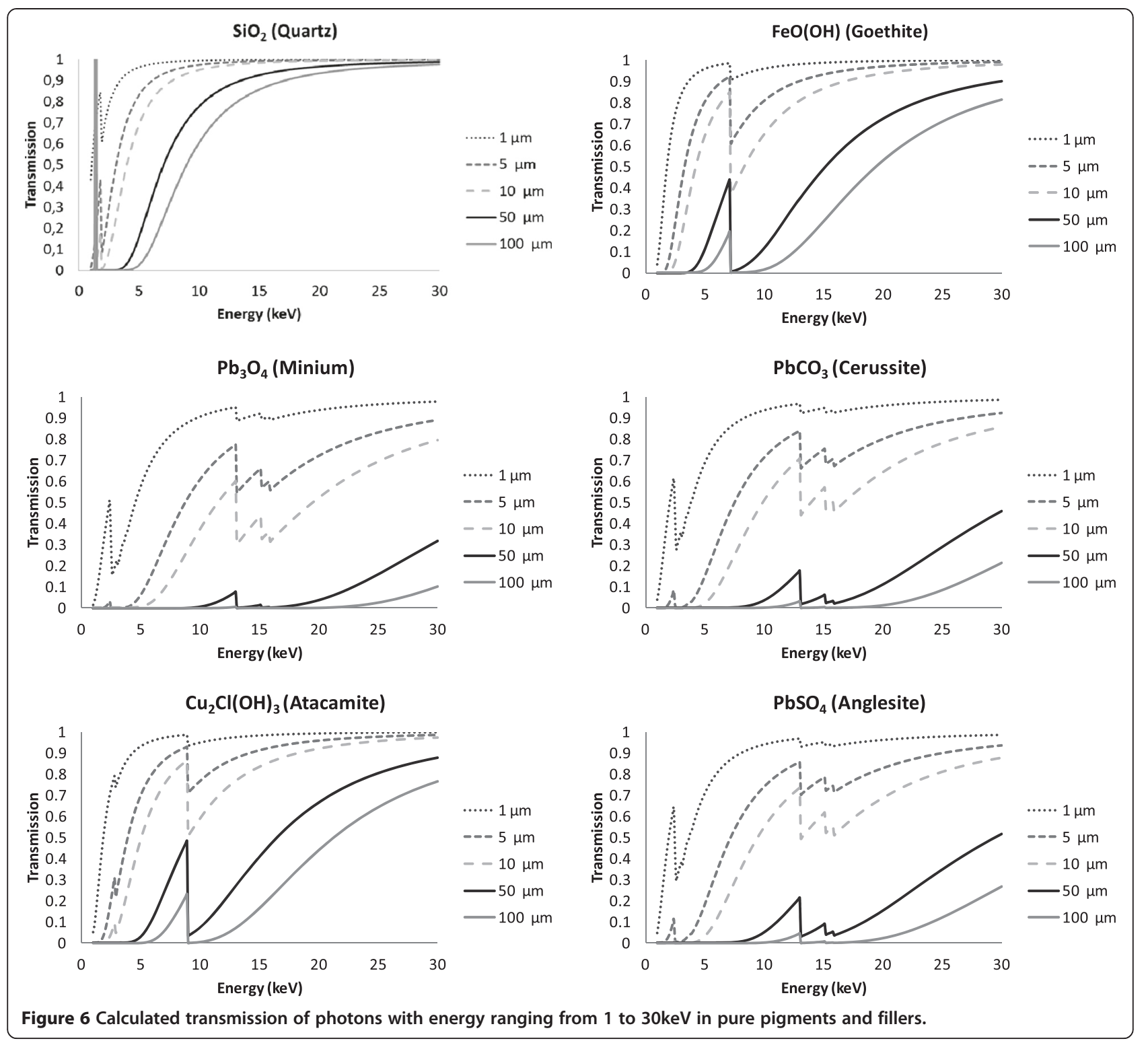

50 and $100 \mu \mathrm{m}$ of different pure pigments as a function of the energy of X-ray photons. Pigment layer thickness respecting transmission limit rules is easily estimated from this figure if looking at the absorption edge of interest as well as the post-edge region. As an example, a $10 \mu \mathrm{m}$ layer of pure goethite $(\mathrm{FeO}(\mathrm{OH}))$ is suitable for the acquisition of XANES at the Fe K-edge in transmission mode, since the ratio of transmission above the Fe K-edge vs. transmission below the edge is of $40 \%$, and transmission in the post-edge region is still of $35 \%$.

\section{New technical imaging capabilities available based on thin-section transmission analyses}

Another advantage of acquiring XANES spectra in transmission is the possibility to go towards 2D XANES. Generally, speciation images are obtained by acquiring $n$
$\mathrm{XRF}$ maps at $\mathrm{n}$ peculiar energies giving the maximum contrast between the different speciations of the probed element, in scanning mode. This approach is efficient if the different species show a pronounced shift of the edge position with the oxidation state since no spectral data are acquired. Moreover, the field of view is limited by the dwell time. In this context the use of ultra fast detectors such as MAIA allow $\mathrm{n}$ to be significantly increased $(>100)$ and to decrease pixel acquisition time providing a better identification of the various species [45]. However, as described above, whatever the detector, these XRF measurements are affected by self-absorption effects when looking at thick and concentrated samples.

An alternative approach exists, based on Transmission X-ray Microscopy (TXM). TXM has been used for more than a decade in the soft X-ray domain and offers unique 
capability for combining spectroscopy and imaging. Its application in the field of $\mathrm{CH}$ is still limited to a few cases, such as the study at the C K-edge of fossil spores [46] or at the Fe L-edges of 450 year old corroded archaeological iron nail [47]. Whereas chemical mapping performed through Soft Transmission X-ray Microscopy technique is a standard technique, performing 2D-XANES is still limited in the hard X-ray range. Recently, different beamlines have explored the possibility to perform hard-X-ray microscopy (TXM) or hard X-ray lensless imaging (fullfield imaging). Currently, three such devices are available at Stanford Synchrotron Radiation Lightsource (SSRL) $[48,49]$, at ANKA [50] and at the ESRF. In a few words, a $2 \mathrm{D}$ camera is used to provide imaging information on a static sample while scanning the energy of the incoming beam around the absorption edge of the element of interest. Thanks to the simultaneous acquisition of millions of pixels, over large sample areas with sub-micron resolution, this technique is very well suited for the study of complex, heterogeneous samples, in which the element of interest is concentrated, which is frequently the case in archaeological materials, and in particular in paintings. This type of set-up has been successfully applied for studying manufacturing processes of roman ceramics [51], applications on paintings follow.

At ID21 beamline, ESRF, the set-up is based on a lensless approach, which accommodates a millimetric beam and spatial resolutions (determined downstream the sample by the collecting optics and the camera) ranging from 0.3 to $1.4 \mu \mathrm{m}$ and fields of view from $600 \mu \mathrm{m}$ up to $2 \mathrm{~mm}$ (cf. experimental section).

First experiments have been carried out with this instrumentation to evaluate the capabilities of the XANES full-field set-up to map the oxidation state of pigments present in painting layer. For the feasibility trial, model painting samples were primarily designed as a biphasic system composed of one layer of manganese dioxide $\left(\mathrm{MnO}_{2}\right)$ and one of manganese sulphate $\left(\mathrm{MnSO}_{4}\right)$, both pigments were mixed with linseed oil. Thin-sections $30 \mu \mathrm{m}$ thick were then prepared with a microtome (Figure 7a). This preparation allows for studying the painting cross-section with a good preservation of the sample spatial structures (Figure 7b). 2D XANES analyses were then performed around Mn K-edge from 6.54 to $6.40 \mathrm{keV}$ in 100 energy steps, in 45 minutes.

Results of full-field acquisition were obtained following two independent approaches (Figure $7 \mathrm{c}$ and $\mathrm{d}$ ): principle component analysis (PCA) [52] combined to subsequent k-means clustering [53] (details can be found in [54]), and least squares linear combination (LSLC) fitting with $\mathrm{MnO}_{2}$ and $\mathrm{MnSO}_{4}$ standards and subsequent R-factor correlation analysis (details can be found in [55]). Both methods give 2D oxidation state mapping of Mn-based pigments with a submicrometric resolution and a field of view of $\sim 1 \mathrm{~mm}^{2}$. From PCA and LSLC results, XANES spectra are respectively extracted from i) a single pixel in each of the two manganese layers and ii) XANES pixels sum of cluster 1 and 2. For single pixel XANES, the SNR allows reliable LSLC fitting with high $\mathrm{R}$-factor values.

Consequently, this procedure allows for highly sensitive and quantitative 2D mapping of the two manganese species and opens new possibilities for historical painting studies.

\section{Micro-X-Ray diffraction \\ Principles of XRD and applications to painting fragments}

XRD is based on the constructive interferences of X-ray elastically scattered by a regular array of atoms. For this study, the diffracted intensity (irradiance) of a monochromatic X-ray beam from a powder is considered under the kinematic approximation. By means of an Xray sensitive detector, information on the scattering material, in particular the identification of the cristallized phased, can be derived from the interference patterns. XRD performed with a synchrotron source presents several advantages compared with conventional sources, among which the brightness which, as for $\mu X R F$, improves the achievable detection limit, acquisition dwell time and lateral resolution. The last two points are the key factors for the implementation of XRD in 2D and 3D mapping modes. Besides, the access to high energies enables the analysis of thick and/or absorbing materials, such as entire paintings [56,57].

In the context of the analysis of paintings, $\mu$ XRD is extensively used for the identification of various crystallized paint ingredients and degradation products. Beyond common pigment identification, $\mu \mathrm{XRD}$ enables to differentiate the main compositional groups, which could be specific of a period, a production process or a geographical origin [58]. For the analysis of degradation products, usually present at low concentrations in micrometric surface layers, where conventional XRD may be insufficient, the micrometric SR beam proved to be a more selective probe suitable to detect those minor phases [15].

\section{Diffraction acquisition modes and related opportunities}

XRD acquisitions, in laboratory or at synchrotron, can be performed in two main configurations: in reflection mode or in transmission mode (Figure 4c).

In reflection mode, the sample (being for example a resin-embedded cross-section [58] or a painting [59]) is oriented at grazing angle $\left(\sim 5-10^{\circ}\right)$ which increases beam spot size at sample surface and enhances sensitivity to the surface topography (Figure 4c, left). Moreover, the diffraction scattering signal at low angle is partially re-absorbed by the resin and the sample itself, therefore limiting the accessible angle range [58]. However, this technique allows 
a)

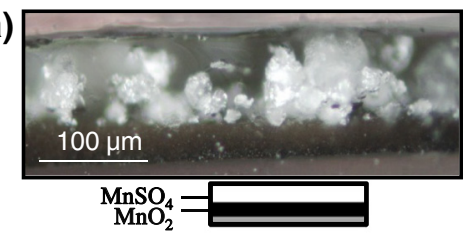

Thin section $(30 \mu \mathrm{m})$ b)

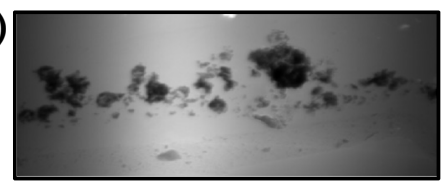

c)
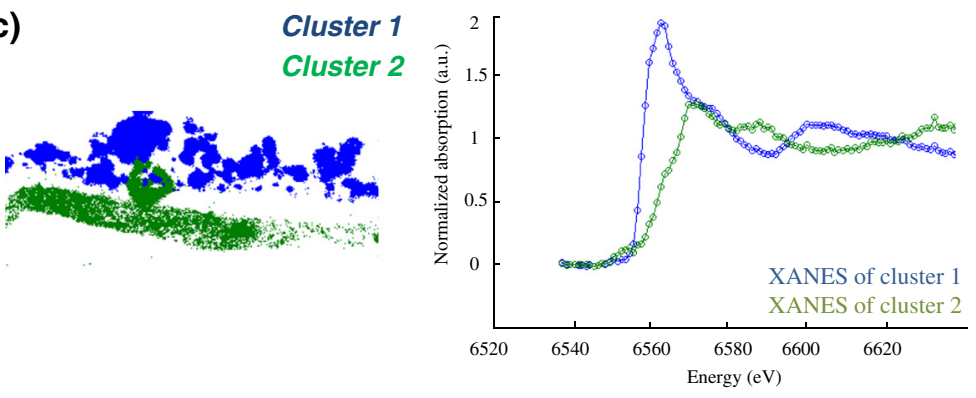

d)

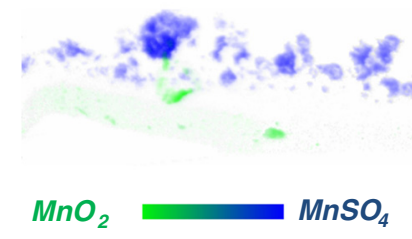

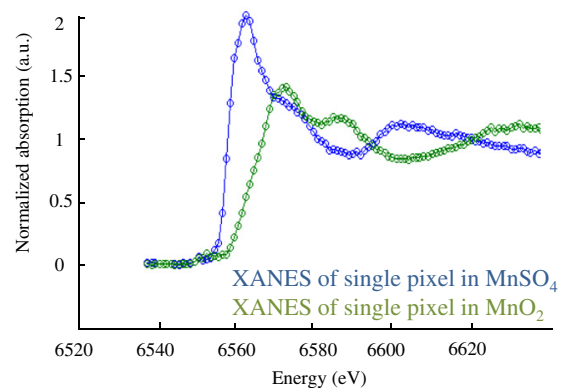

Figure 7 Example of XANES full-field results acquired on mock-up painting sample composed of two Mn-based pigment layer as observed in a) an optical image of a $30 \mu \mathrm{m}$ thick section composed of $\mathrm{MnO}_{2}$ and $\mathrm{MnSO}_{4}$ layers as illustrated in the schema, b) one of the hundreds transmission image of the sample recorded by a $2 \mathrm{D}$ detector (pixel size: $0.7 \times 0.7 \mu \mathrm{m}^{2}$ ) at $\mathrm{E}=6.45 \mathrm{keV}, \mathrm{c}$ ) PCA and subsequent clustering results for localisation of the two $\mathrm{Mn}$-based species with correlative sum of pixel XANES, d) LSLC results using $\mathrm{MnO}_{2}$ and $\mathrm{MnSO}_{4}$ reference standards for localisation and quantification of $\mathbf{M n}$-based species into the sample. From localisation, one pixel XANES spectrum was extracted from each pigment phases.

working on cross-section already prepared for previous microscopic observation without need for further sample preparation.

A second approach consists of using $\mu$-XRD in transmission mode (Figure $4 \mathrm{c}$, right), the surface of the section can then be perpendicular to the beam. This allows reaching ultimate resolution in both lateral and in-depth directions, and acquiring XRD rings over the full $2 \theta$ range. However, with contrast to the reflection approach, this approach may be more demanding in term of sample preparation.

\section{Determination of an optimum thickness for $\mu \mathrm{XRD}$ analyses}

Contrarily to $\mu$ FTIR and $\mu$ XANES, in the case of $\mu$ XRD analyses performed on paint samples, the energy of the incoming X-ray is not severely imposed by spectroscopic constraints. The use of harder X-ray will allow the analysis of thicker samples. This explains why $\mu \mathrm{XRD}$ is sometimes applied in transmission, to thick polished sections $(\geq 100 \mu \mathrm{m})$ [58].

However, as discussed previously for XRF studies, the controlled thickness of thin-sections may limit averaging effect along beam path. This point is crucial when dealing with micrometric painting or degradation layer.

The optimum thickness can be theoretically estimated considering the two contrary effects: the thicker the sample, the more scattered (linear with the thickness), but also the more absorbed (following equation 1) [60]. Properly choosing both wavelength and sample thickness allows absorption to be kept to an acceptable value, avoiding peak shift and intensity corrections. This regime is expected for $\mu_{\mathrm{li}} \mathrm{t}=1$ corresponding to $33 \%$ transmission of incoming beam across the sample [61].

Most XRD experiments performed on painting fragments are carried out with an incident beam energy fixed to about 15 or $30 \mathrm{keV}$. The classical thickness expected 
for maximum diffracted intensity in transmission mode is evaluated at those two energies for the pigments presented in the upper section, using transmission values plotted in Figure 6. 67\% of absorption is expected at $15 \mathrm{keV}$ and $30 \mathrm{keV}$ respectively for: $60 \mu \mathrm{m}$ and $400 \mu \mathrm{m}$ thick atacamite layer, $30 \mu \mathrm{m}$ (calculated at $13 \mathrm{keV}$ in order to avoid L absorption edges) and $150 \mu \mathrm{m}$ thick for the three lead-based pigments, $70 \mu \mathrm{m}$ and $500 \mu \mathrm{m}$ thick goethite layer, $700 \mu \mathrm{m}$ and $5 \mathrm{~mm}$ thick quartz layer.

\section{Combining different SR-based techniques}

From the previous discussion, each SR-based microanalytical technique will emphasize a different aspect of the painting properties. Accordingly, to obtain the most complete overview of the painting techniques, the combination of these different techniques is essential. Indeed, a full description of the painting composition is a real advantage because this enables understanding how the different ingredients (being original pigments, binders, varnishes, restoration products, degradation composed, etc.) are related to the different chemical and physical processes implied during creation and degradation of the artworks. A very good example of this multi-facet composition and interaction is given by a recent study of the degradation of the cadmium-based yellow pigment in Van Gogh's paintings. The stability of an inorganic pigment $(\mathrm{CdS})$ was affected by the presence of an organic varnish applied for conservation purposes, leading to the formation of hybrid compounds: $\mathrm{Cd}$ oxalates [12]. This example illustrates the necessity for combining $\mu \mathrm{XRF}, \mu \mathrm{XRD}, \mu \mathrm{XANES}$ and $\mu$ FTIR to understand the full picture of the organic/ inorganic, crystallized/amorphous materials composing the painting, and to get insight into the way they interact.

As detailed above and in a previous paper [17], obtaining thin-sections from painting fragments for combined analytical approach is not straightforward. Considering that requirements in terms of section thickness and invasiveness effects of sample preparation are not necessarily shared by the different analytical techniques, different cases are distinguished (Figure 8).

If a unique technique is required to answer the analytical question, a preparation optimized for this single technique is implemented.

When the study necessitates the combination of different techniques, determining if a single sample can be analysed with all the techniques, or if adapted sections should and can be specifically prepared is a major question, for which both sample preparation strategy and thickness are key factors. Ideally, when both are compatible, working with a single section is preferable because:

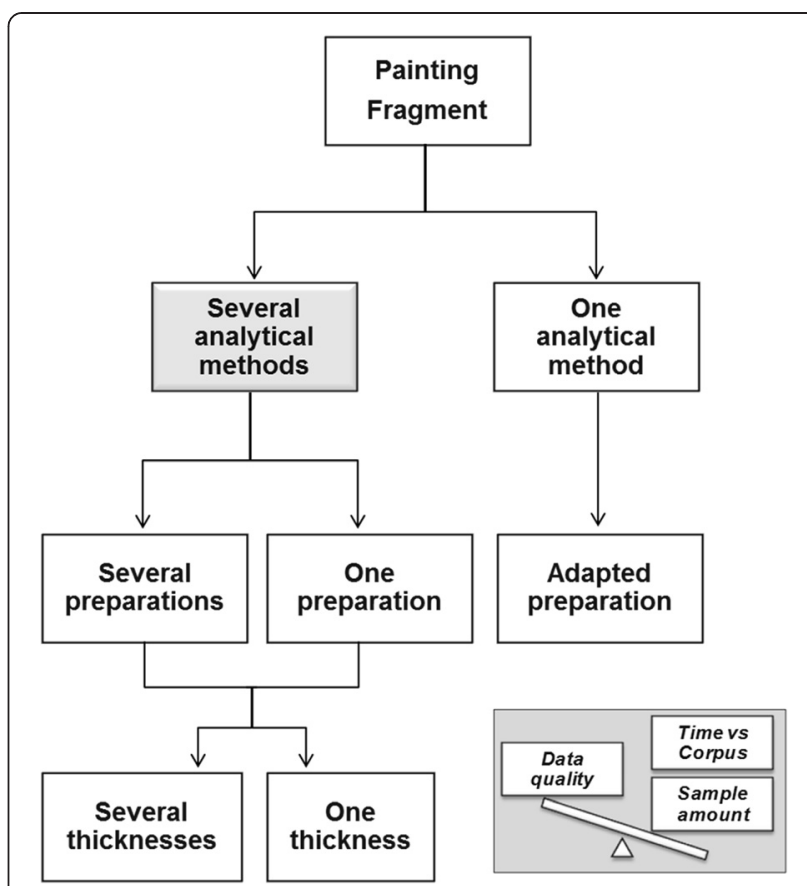

Figure 8 Schematic view of the main strategies for the combined analysis of painting thin-sections.

- it reduces the amount of sample needed. Indeed, fragments from historical paintings can be too small to allow any splitting into aliquots.

- it is less time consuming. This should be considered while studying a large corpus with a large set of techniques.

- it allows a direct spatial combination of hyperspectral data.

However, attention should be paid to the order of the different analyses so that the techniques less disposed to modify the sample are applied first. As FTIR acquired in transmission mode does not affect the materials during analysis (unlike X-ray analyses, under certain conditions), this technique should be performed first in a combined approach. Then $\mu$ XRF acquisition may help in the definition of areas of interest for XANES or XRD measurements, and must consequently be performed previously or simultaneously to last XANES and XRD measurements.

When technique requirements differ, an adapted strategy may be implemented. In the case of different optimum thickness, sections from the same fragment with appropriate thickness can be prepared. However if sample preparation requirements differ, another sample fragment can be prepared following a different sample preparation protocol.

In this context, the problematic, the corpus and the typical fragment size, as well as the required data quality 
may lead to a compromise over the set of techniques, with the priority given to the one which will best answer the problematic.

\section{Conclusion and perspectives}

SR based $\mu$ FTIR, $\mu$ XRF, XANES and XRD are increasingly employed, for the study of paintings, providing insight into historical practices and into degradation mechanisms. Their combination offers a much more complete picture of chemical composition and reactions involved in the artwork all along its history. In the present paper, the advantages offered by the analysis of thin-sections, instead of cross-sections are presented. In summary, advantages were highlighted concerning:

- spatial resolution, in particular by limiting in-depth averaging and by avoiding chromaticity of penetration depth for ATR-FTIR, $\mu$ XRF and $\mu$ XANES.

- results reliability and quantification, by limiting matrix absorption effects in $\mu \mathrm{XRF}, \mu \mathrm{XANES}$ and $\mu \mathrm{XRD}$, self-absorption effects in $\mu$ XANES acquired in $\mu \mathrm{XRF}$ mode, and by allowing the direct comparison of $\mu$ FTIR spectrum acquired in transmission with libraries.

- the possibility to perform fast and large field of view 2D-XANES.

A supplementary discussion was addressed to determine optimum thickness for single microanalysis as a function of the incoming photons energy and of the sample composition. In a few words:

- $\mu$ FTIR is one of the most demanding techniques, with thickness requirements between 0.5-20 $\mu \mathrm{m}$.

Thin-section analysis offers new opportunities in terms of spatial resolution for all X-ray techniques, but supplementary advantages were highlighted specifically for the examples and the energy range considered (from 2 to $9 \mathrm{keV}$ ) in this study:

- Concerning $\mu \mathrm{XRF}$, the possibility to extend analysis to more quantitative results has been proposed when applied to a thin-sample case $(<5 \mu \mathrm{m})$ or to an intermediate case $(5-20 \mu \mathrm{m})$.

- Concerning $\mu$ XANES, for samples with concentrated elements of interest, transmission measurements should be preferred limiting data acquisition to section thickness ranging from 1 to $20 \mu \mathrm{m}$. But performing $\mu$ XANES analyses in XRF mode on thin-sections of appropriate thickness allows also substantially reducing the self-absorption effect, in this case section thickness represents only a few microns $(<5 \mu \mathrm{m})$.
- Finally concerning $\mu \mathrm{XRD}$, thickness requirements are similar to the ones of $\mu$ XANES. However, as the energy beam is not sample-dependant, more flexibility is offered regarding section thickness. Higher energies are usually used which increase the optimum thickness values, e.g. for an energy ranging from 15 to $30 \mathrm{keV}$ thickness may range from tens to a few hundred of microns for the examples considered.

Finally, out of the SR context the preparation and analysis of thin-sections could be of interest for other imaging techniques increasingly used for the study of artistic materials. It is already the case for Transmission Electron Microscopy for which the preparation of ultra thin sections is a standard practice. Thus many other microscopy-based techniques may benefit from the analysis of thin-sections, e.g. staining based techniques [62], Particle Induced X-ray Emission, or the Scanning Transmission Ion Microscopy [63].

Moreover whereas in the present paper, the discussion was focused on painting materials, this work could be easily extended to other artistic materials (e.g. ceramics, glasses, fibers, polymer-based modern materials).

\section{Experimental section}

The results presented in this study were obtained at the ID21 beamline, ESRF.

This beamline hosts two independent end-stations, one in the tender X-ray domain (2-9 keV) (Figure 9), and the second one in the mid-infrared domain (4000$700 \mathrm{~cm}^{-1}$ ).

The X-ray microscope is on an insertion device; X-ray energy is defined thanks to a fixed exit double crystal monochromator $(\mathrm{Si}(111))$; the beam size is modulated by a set of pinholes (a few tens up to $200 \mu \mathrm{m}$ ) or focused down to less than $1 \mu \mathrm{m}$ thanks to different optics (namely a set of Fresnel Zone Plates, or a Kirkpatrick-Baez mirrors system). The beam size is typically $0.2 \mu \mathrm{m}$ ver.. $\times 0.6 \mu \mathrm{m}$ hor. with a flux ranging from $10^{9}$ to $10^{10} \mathrm{ph} / \mathrm{s}$. A photodiode upstream the sample allows a continuous measurement of the incoming beam intensity. The samples are mounted under vacuum, in a vertical plan, at an angle of $62^{\circ}$ with respect to the beam. The transmission intensity is measured using a photodiode downstream the sample, while the fluorescence is detected using a Silicon Drift Diode detector. A video-microscope allows an in-situ observation of the sample.

In the full-field instrument [37], the beam size is defined using slits $\left(1 \times 1 \mathrm{~mm}^{2}\right)$ and the beam's spatial structures are smoothed using an X-ray decoheror (graphite foil). Samples are mounted vertically, perpendicular to the beam and radiographs are acquired thanks to a $2 \mathrm{D}$ detecting ensemble made of a scintillator, a magnifying objective x10/N.A 0.42 and a sCMOS camera (PCO- 


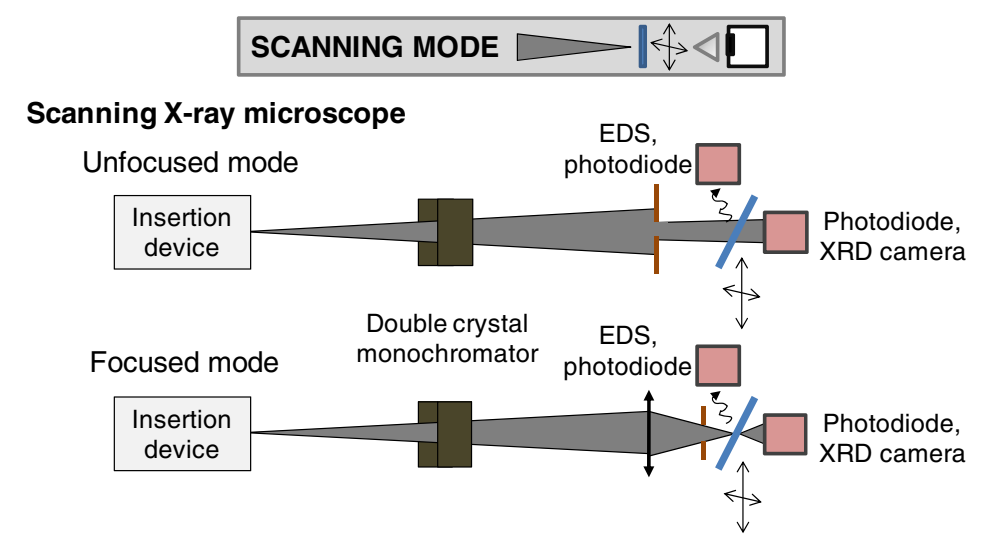

FULL-FIELD IMAGING $\square \mid \square \square$

Full-field X-ray microscope
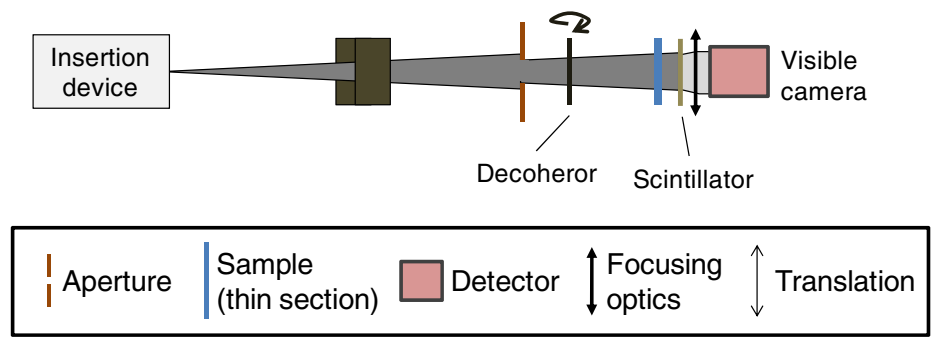

Figure 9 Two main data collection modalities available at the ID21 beamline: scanning and full-field imaging. Sketches illustrating the different instrument configurations for $\mu$ XRF and $\mu$ XANES analyses.

edge). It provides pixel size of $0.6 \times 0.6 \mu \mathrm{m}^{2}$ and field of view of $1 \mathrm{~mm}^{2}$.

For both scanning and full-field microscopes, samples are usually mounted as a sandwich in between two pure foils of Ultralene (Spex, CertiPrep). Special sample holders allow transferring the sample from one microscope to another and are compatible as well with the visible light microscope (Zeiss).

$\mu \mathrm{XRF}$, XANES spectra and maps are analysed using the PyMca and TXM-Wizard software package [64].

The ID21 FTIR end-station at ESRF is primarily composed of a commercial FTIR spectro-microscope from Thermo with a Nicolet Nexus infrared bench associated with an infrared Continu $\mu \mathrm{m}$ microscope [65]. The infrared beam is emitted from the short straight section (focusing electron lenses) upstream of a bending magnet. An extraction mirror, flat un-cooled aluminium mirror with a horizontal slot, lets the energetic part of the synchrotron light go through for absorption $2.5 \mathrm{~m}$ further down. The edge radiation is collected, collimated and transferred to the spectrometer and microscope using a set of 12 mirrors. In the microscope, two $\times 32$ Schwarzschild objectives are used in a confocal mode and an aperture defines the spot size illuminating the sample. In the mid-IR domain, the signal is detected using a liquid
$\mathrm{N} 2$ cooled single element $50 \mu \mathrm{m}$ MCT detector. In this configuration, the typical beam size is diffraction limited in the range of 3 to $10 \mu \mathrm{m}$. For mid-IR, measurements can be carried out in transmission, reflection, transreflectance or ATR mode as well.

$\mu$ FTIR spectra and maps are analysed using the PyMca and OMNIC software package.

\section{Competing interest}

The authors declare that they have no competing interests.

\section{Authors' contributions}

EP performed the experimental and writing work. BF and MS supported the full-field experiments.YT provided Bamyian's samples and related interpretation. MC and FS participated in paper design and coordination and helped to draft the manuscript. All authors read and approved the final manuscript.

\section{Acknowledgment}

The European Synchrotron Radiation Facility is thanked for providing beamtime (EC-977 and in-house research), assistance and economical support.

\section{Author details}

'European Synchrotron Radiation Facility, 71, avenue des Martyrs, Grenoble F-38000, France. ${ }^{2}$ Laboratoire de Physique des Solides, Cedex, UMR 8502 Université Paris Sud, Orsay 91405, France. ${ }^{3}$ Graduate school of Humanities and Social Sciences, University of Tsukuba, 1-1-1 Tenno-dai, Tsukuba, Ibaraki 305-8571, Japan. ${ }^{4}$ LAMS (Laboratoire d'Archéologie Moléculaire et Structurale) UMR-8220, 3 rue Galilée, Ivry-sur-Seine 94200, France. 
Received: 20 May 2014 Accepted: 4 December 2014

Published online: 21 January 2015

\section{References}

1. Bertrand L, Cotte M, Stampanoni M, Thoury M, Marone F, Schöderg S. Development in synchrotron studies of ancient and historical materials. Physics Reports. 2012;519(2):51-96.

2. Cotte M, Susini J, Solé VA, Taniguchi Y, Chillida J, Checroum E, et al. Applications of synchrotron-based micro-imaging techniques to the chemical analysis of ancient paintings. J Anal At Spectrom. 2008;23:820-8.

3. Kiernan JA. Histological and Histochemical Methods: Theory and Practice. 4th ed. Oxford, UK: Scion Publishing; 2008.

4. Reedy CL. Thin-section petrography in studies of cultural materials. J Am Inst Conserv. 1994;33(2):115-29.

5. Peterson SE. Thin-Section Petrography of Ceramic Materials. In: Instap archaeological excavation manual 2. Philadelphia, Pennsylvania: INSTAP Academic Press; 2009.

6. Echard JP, Bertrand L, von Bohlen A, Le Hô AS, Paris C, Bellot-Gurlet L, et al The Nature of the Extraordinary Finish of Stradivarius Instruments. Angew Chem. 2010;49(1):197-201.

7. Cotte M, Walter $P$, Tsoucaris $G$, Dumas P. Studying skin of an Egyptian mummy by infrared microscopy. Vib Spectrosc. 2005;38(1-2):159-67.

8. Bertrand L, Vichi A, Doucet J, Walter P, Blanchard P. The fate of archaeological keratin fibres in a temperate burial context: microtaphonomy study of hairs from Marie de Bretagne (15th C., Orléans, France). J Archaeol Sci. 2014;42:487-99.

9. Lebon M, Muller K, Bahain J-J, Frohlich F, Falgueres C, Bertrand L, et al. Imaging fossil bone alterations at the microscale by SR-FTIR microspectroscopy. J Anal At Spectrom. 2011;26(5):922-9.

10. Kennedy CJ, Hiller JC, Lammie D, Drakopoulos M, Vest M, Cooper M, et al. Microfocus X-ray Diffraction of Historical Parchment Reveals Variations in Structural Features through Parchment Cross Sections. Nano Lett. 2004;4(8):1373-80.

11. Salvadó N, Butí S, Cotte M, Cinque G, Pradell T. Shades of green in 15th century paintings: combined microanalysis of the materials using synchrotron radiation XRD. FTIR and XRF Applied Physics A. 2012;111(1):47-57.

12. Van der Snickt G, Janssens K, Dik J, De Nolf W, Vanmeert F, Jaroszewicz J, et al. Combined use of Synchrotron Radiation Based Micro-X-ray Fluorescence, Micro-X-ray Diffraction, Micro-X-ray Absorption Near-Edge, and Micro-Fourier Transform Infrared Spectroscopies for Revealing an Alternative Degradation Pathway of the Pigment Cadmium Yellow in a Painting by Van Gogh. Anal Chem. 2012;84(23):10221-8.

13. Salvadó N, Butí S, Nicholson J, Emerich H, Labrador A, Pradell T. Identification of reaction compounds in micrometric layers from gothic paintings using combined SR-XRD and SR-FTIR. Talanta. 2009;79(2):419-28.

14. van der Weerd J. Microspectroscopic analysis of traditional oil paint. In: Ph. D. Thesis. Amsterdam, Holand: Institute for Atomic and Molecular Physics (AMOLF); 2002.

15. Radepont $M$, de Nolf $W$, Janssens $K$, Van der Snickt G, Coquinot $Y$, Klaassen $L$, et al. The use of microscopic $X$-ray diffraction for the study of $\mathrm{HgS}$ and its degradation products corderoite ([small alpha]-Hg3S2Cl2), kenhsuite ([gamma]- $\mathrm{Hg} 3 \mathrm{~S} 2 \mathrm{Cl} 2)$ and calomel $(\mathrm{Hg} 2 \mathrm{Cl} 2)$ in historical paintings. J Anal At Spectrom. 2011;26(5):959-68.

16. Cotte M, Checroun E, Mazel V, Solé VA, Richardin P, Taniguchi Y, et al. Combination of FTIR and X-rays synchrotron-based micro-imaging techniques for the study of ancient paintings. A practical point of view. ePRESERVATIONScience. 2009;61-9.

17. Pouyet E, Lluveras-Tenorio A, Nevin A, Saviello D, Sette F, Cotte M. Preparation of thin-sections of painting fragments: classical and innovative strategies. Anal Chim Acta. 2014;822:51-9.

18. Herrera LK, Montalbani S, Chiavari G, Cotte M, Sole VA, Bueno J, et al. Advanced combined application of mu-X-ray diffraction/mu-X-ray fluorescence with conventional techniques for the identification of pictorial materials from Baroque Andalusia paintings. Talanta. 2009;80(1):71-83.

19. van der Weerd J, Brammer H, Boon J, Heeren R. Fourier transform infrared microscopic imaging of an embedded paint cross-section. Appl Spectrosc. 2002;56(3):275-83.

20. Cotte M, Dumas P, Richard G, Breniaux R, Walter P. New insight on ancient cosmetic preparation by synchrotron-based infrared microscopy. Anal Chim Acta. 2005:553(1-2):105-10

21. Salvado N, Buti S, Tobin MJ, Pantos E, Pradell T. The nature of medieval synthetic pigments: the capabilities of SR-infrared spectroscopy. IRUG6 Conference, 2005;296-301.
22. Casadio F, Toniolo L. The analysis of polychrome works of art : 40 years of infrared spectroscopic investigations. J Cult Herit. 2001;2(1):71-8.

23. Lepot K, Benzerara K, Rividi N, Cotte M, Brown Jr GE, Philippot P. Organic matter heterogeneities in $2.72 \mathrm{Ga}$ stromatolites: Alteration versus preservation by sulfur incorporation. Geochim Cosmochim Acta. 2009;73 (21):6579-99.

24. Spring M, Ricci C, Peggie D, Kazarian S. ATR-FTIR imaging for the analysis of organic materials in paint cross sections: case studies on paint samples from the National Gallery. London Analytical and Bioanalytical Chemistry. 2008;392(1-2):37-45

25. Derrick M, Stulik D, Landry JM. Infrared spectroscopy in conservation science. In: T.G.c. institute, editor. Scientific Tools for conservation. Los Angeles: The Guetty conservation institute; 1999. p. 235.

26. Prati S, Rosi F, Sciutto G, Oliveri P, Catelli E, Miliani C, et al. Evaluation of the effect of different paint cross section preparation methods on the performances of Fourier transformed infrared microscopy in total reflection mode. Microchem J. 2013;110:314-9.

27. van der Weerd J, Heeren RM, Boon JJ. Preparation methods and accessories for the infrared spectroscopic analysis of multi-layer paint films. Stud Conserv. 2004:49(3):193-210.

28. Nevin A. ATR and reflectance micro-FTIR: an exploration of their suitability for the analysis of wall paintings cross-sections. conservation of wall painting department, Courtauld Institute of Art, 2004.

29. Joseph E, Prati S, Sciutto G, loele M, Santopadre P, Mazzeo R. Performance evaluation of mapping and linear imaging FTIR microspectroscopy for the characterisation of paint cross sections. Anal Bioanal Chem. 2010;396:899-910.

30. Mazzeo R, Joseph E, Prati S, Millemaggi A. Attenuated Total ReflectionFourier transform infrared microspectroscopic mapping for the characterisation of paint cross-sections. Anal Chim Acta. 2007;599(1):107-17.

31. Mazze R, Prati S, Quaranta M, Joseph E, Kendix E, Galeotti M, Attenuated total reflection micro FTIR characterisation of pigment-binder interaction in reconstructed paint films. Analytical and Bioanalytical Chemistry, 2008: p. 1-12

32. Joseph E, Ricci C, Kazarian S, Mazzeo R, Prati S, loele M. Macro-ATR-FT-IR spectroscopic imaging analysis of paint cross-sections. Vib Spectrosc. 2010;53(2):274-8.

33. Castro K, Perez M, Rodriguez-Laso MD, Madariaga JM. FTIR spectra database of inorganic art materials. Anal Chem. 2003;75(9):214A-21A.

34. Nasse MJ, Walsh MJ, Mattson EC, Reininger R, Kajdacsy-Balla A, Macias V, et al. High-resolution Fourier-transform infrared chemical imaging with multiple synchrotron beams. Nat Meth. 2011:8(5):413-6.

35. Patterson CS, Carson D, Phenix A, Khanjian H, Trentelman K, Mass J, et al. Synchrotron-based Imaging FTIR Spectroscopy in the Evaluation of Painting Cross-sections. e-Preservation Science, 2013. 10

36. Tsang J-S, Cunningham RH. Some improvements in the study of cross sections. J Am Inst Conserv. 1991:30(2):163-77.

37. Cotte $M$, Welcomme $E$, Solé VA, Salomé M, Menu M, Walter $P$, et al. Synchrotron-based X-ray spectromicroscopy used for the study of an atypical micrometric pigment in 16th century paintings. Anal Chem. 2007;79:6988-94

38. Janssens K, Vittiglio G, Deraedt I, Aerts A, Vekemans B, Vincze L, et al. Use of microscopic XRF for non-destructive analysis in art and archaeometry. X-Ray Spectrom. 2000;29(1):73-91.

39. Van Grieken R, Markowicz A. Handbook of X-ray Spectrometry. 2001: CRC Press.

40. Cotte M, Susini J, Dik J, Janssens K. Synchrotron-based X-ray absorption spectroscopy for art conservation: looking back and looking forwards. Acc Chem Res. 2010;43(6):705-14

41. Cotte M, Susini J, Metrich N, Moscato A, Gratziu C, Bertagnini A, et al. Blackening of Pompeian cinnabar paintings: X-ray microspectroscopy analysis. Anal Chem. 2006;78(21):7484-92.

42. Robinet $L$, Spring M, Pagès-Camagna S, Vantelon D, Trcera N. Investigation of the Discoloration of Smalt Pigment in Historic Paintings by Micro-X-ray Absorption Spectroscopy at the Co K-Edge. Anal Chem. 2011;83(13):5145-52.

43. Calvin S. XAFS for Everyone. 2013: CRC Press.

44. Newville M. Fundamentals of XAFS. Editor: U.o. Chicago; 2004. p. 1-43.

45. Ryan CG, Siddons DP, Kirkham R, Dunn PA, Kuczewski A, Moorhead G, et al. The New Maia Detector System: Methods For High Definition Trace Element Imaging Of Natural Material. AIP Conference Proceedings. 2010;1221(1)9-17.

46. Bernard S, Benzerara K, Beyssac O, Brown Jr G, Stamm LG, Duringer P. Ultrastructural and chemical study of modern and fossil sporoderms by Scanning Transmission X-ray Microscopy (STXM). Rev Palaeobot Palynol. 2009;156(1):248-61. 
47. Michelin A, Drouet E, Foy E, Dynes J, Neff D, Dillmann P. Investigation at the nanometre scale on the corrosion mechanisms of archaeological ferrous artefacts by STXM. J Anal At Spectrom. 2013;28(1):59-66.

48. Andrews JC, Almeida E, van der Meulen MCH, Alwood JS, Lee C, Liu Y, et al. Microscopy and Microanalysis. 2010;16:327.

49. Meirer F, Cabana J, Liu Y, Mehta A, Andrews JC, Pianetta P. Threedimensional imaging of chemical phase transformations at the nanoscale with full-field transmission X-ray microscopy. J Synchrotron Radiat. 2011;18 (5):773-81.

50. Mangold, S., R. Steininger, T. dos Santos Rolo, and J. Göttlicher. Full field spectroscopic imaging at the ANKA-XAS-and-SUL-X-Beamlines. in Journal of Physics: Conference Series. 2013. IOP Publishing.

51. Meirer F, Liu Y, Pouyet E, Fayard B, Cotte M, Sanchez C, et al. Full-field XANES analysis of Roman ceramics to estimate firing conditions-A novel probe to study hierarchical heterogeneous materials. J Anal At Spectrom. 2013;28(12):1870-83.

52. Jolliffe I. Principal component analysis. 2005: Wiley Online Library.

53. Johnson RA, Wichern DW. Applied multivariate statistical analysis. Vol. 5. Upper Saddle River, NJ: Prentice hall; 2002

54. Boesenberg U, Meirer F, Liu Y, Shukla AK, Dell'Anna R, Tyliszczak T, et al. Mesoscale Phase Distribution in Single Particles of LiFePO4 following Lithium Deintercalation. Chem Mater. 2013:25(9):1664-72.

55. Liu Y, Meirer F, Williams PA, Wang J, Andrews JC, Pianetta P. TXM-Wizard: a program for advanced data collection and evaluation in full-field transmission X-ray microscopy. J Synchrotron Radiat. 2012;19(2):281-7.

56. De Nolf W, Dik J, Van der Snickt G, Wallert A, Janssens K. High energy X-ray powder diffraction for the imaging of (hidden) paintings. J Anal At Spectrom. 2011;26(5):910-6.

57. De Nolf W, Vanmeert F, Janssens K. XRDUA: crystalline phase distribution maps by two-dimensional scanning and tomographic (micro) X-ray powder diffraction. J Appl Crystallogr. 2014:47(3):1107-17.

58. Welcomme E, Walter $P$, Bleuet $P$, Hodeau $J$, Dooryhee $E$, Martinetto $P$, et al. Classification of lead white pigments using synchrotron radiation micro $X$ ray diffraction. Appl Phys A Mater Sci Process. 2007:89(4):825-32.

59. Dooryhée $E$, Anne M, Bardiès I, Hodeau JL, Martinetto $P$, Rondot $S$, et al. Non-destructive synchrotron X-ray diffraction mapping of a Roman painting. Appl Phys A Mater Sci Process. 2005:81(4):663-7.

60. He BB. Two-dimensional X-ray Diffraction. 2011: John Wiley \& Sons

61. Sabine TM, Hunter BA, Sabine WR, Ball CJ. Analytical Expressions for the Transmission Factor and Peak Shift in Absorbing Cylindrical Specimens. J Appl Crystallogr. 1998;31(1):47-51.

62. Crina Anca Sandu I, de Sá MH, Pereira MC. Ancient '́ilded' art objects from European cultural heritage: a review on different scales of characterization. Surface and Interface Analysis. 2011;43(8)1134-1151.

63. Beck $L$, de Viguerie $L$, Walter $P$, Pichon L, Gutiérrez PC, Salomon J, et al. New approaches for investigating paintings by ion beam techniques. Nuclear Instruments and Methods in Physics Research Section B: Beam Interactions with Materials and Atoms. 2010;268(11-12):2086-91.

64. Sole VA, Papillon E, Cotte M, Walter P, Susini J. A multiplatform code for the analysis of energy-dispersive $X$-ray fluorescence spectra. Spectrochim Acta B At Spectrosc. 2007;62(1):63-8

65. Susini J, Scheidt K, Cotte M, Dumas P, Polack F, Chubar O. Why infrared spectromicroscopy at the ESRF? ESRF Newsletter. 2005:41:24-5.

Publish with ChemistryCentral and every
scientist can read your work free of charge
"Open access provides opportunities to our
colleagues in other parts of the globe, by allowing
anyone to view the content free of charge."
W. Jeffery Hurst, The Hershey Company.
- available free of charge to the entire scientific community
- peer reviewed and published immediately upon acceptance
- cited in PubMed and archived on PubMed Central
- yours - you keep the copyright
Submit your manuscript here:
http://www.chemistrycentral.com/manuscript/

